\title{
Key drivers and economic consequences of high-end climate scenarios: uncertainties and risks
}

\author{
Kirsten Halsnæs*, Per Skougaard Kaspersen, Martin Drews \\ Climate Change and Sustainable Development Group, Department of Management Engineering, \\ Technical University of Denmark, Building 426, Produktionstorvet, 2800 Kgs. Lyngby, Denmark
}

\begin{abstract}
The consequences of high-end climate scenarios and the risks of extreme events involve a number of critical assumptions and methodological challenges related to key uncertainties in climate scenarios and modelling, impact analysis, and economics. A methodological framework for integrated analysis of extreme events and damage costs is developed and applied to a case study of urban flooding for the medium sized Danish city of Odense. Moving from our current climate to higher atmospheric greenhouse gas (GHG) concentrations including a $2^{\circ}, 4^{\circ}$, and a high-end $6^{\circ} \mathrm{C}$ scenario implies that the frequency of extreme events increase beyond scaling, and in combination with economic assumptions we find a very wide range of risk estimates for urban precipitation events. A sensitivity analysis addresses 32 combinations of climate scenarios, damage cost curve approaches, and economic assumptions, including risk aversion and equity represented by discount rates. Major impacts of alternative assumptions are investigated. As a result, this study demonstrates that in terms of decision making the actual expectations concerning future climate scenarios and the economic assumptions applied are very important in determining the risks of extreme climate events and, thereby, of the level of cost-effective adaptation seen from the society's point of view.
\end{abstract}

KEY WORDS: Climate scenarios $\cdot$ Extremes $\cdot$ Risks $\cdot$ Damage and welfare costs $\cdot$ Uncertainties

\section{INTRODUCTION}

It is well documented that climate change is likely to influence the frequency and severity of some extreme weather and climate events regionally ${ }^{1}$ (IPCC 2012). The projected trends in extremes often show a positive correlation with increasing concentrations of atmospheric greenhouse gasses; hence, the most severe changes are projected under high-end scenarios like the RCP8.5 Representative Concentration Pathway (Meinshausen et al. 2011). In this study we address the evaluation of societal risks, recognizing the fact that despite the inherently low probabilities of

\footnotetext{
${ }^{1}$ 'Extreme events' are here defined as specific outcomes of individual or combinations of climate variables belonging to the tails of a given probability distribution
}

*Corresponding author: khal@dtu.dk extreme events, the economic consequences to society can be very high. Assessing such risks involves specific methodological challenges related to key uncertainties and to economic assumptions. These are again related to the multiple elements involved in climate change impact studies, frequently visualized as a 'cascade' of uncertainties (e.g. Wilby \& Dessai 2010). Methodologically, in the cascading picture, uncertainty propagates through the different interlinked steps in a 'top-down' assessment of climate risks, ranging from socio-economic scenarios through emission scenarios, global and regional climate model projections, and impact models to local impacts and possibly adaptation responses. The uncertainties involved are however of a different nature dependent on disciplines, modelling tools, and approaches applied (IPCC 2005, Refsgaard et al. 2013). Thus some of the uncer-

() The authors 2015. Open Access under Creative Commons by Attribution Licence. Use, distribution and reproduction are unrestricted. Authors and original publication must be credited. 
tainties reflect parameter uncertainties while others are of a more structural character, such as uncertainties related to economic valuation, risk perceptions and preferences (Weitzman 2011). All together this plethora of uncertainties provides a basis for a very wide range of climate change risk estimates.

The present study explores an integrated methodological framework drawn from the cascading picture for assessing the risks of extreme climate events with high consequences, and applies the framework to a real case study of pluvial flood risks in a medium sized Danish city. A systematic assessment is carried out of how risk estimates and uncertainties are related to climate scenario- and impact uncertainties and, in particular, to economic assumptions. Four different climate scenarios are considered: a reference case reflecting current climate conditions, a $2^{\circ} \mathrm{C}$ and a $4^{\circ} \mathrm{C}$ scenario corresponding to the $\mathrm{RCP} 4.5$ and RCP8.5 scenarios, respectively (IPCC 2013), and finally a special $6^{\circ} \mathrm{C}$ climate scenario provided by the Danish Meteorological Institute (Christensen et al. 2015, this Special). We investigate the economic consequences of extreme events - these are, as mentioned above, considered as part of an integrated assessment where climate and impact models are linked to economic models. The methodological framework we use for linking physical and economic models are inspired by a paper by Weitzman (2011) describing the role of 'fat-tailed uncertainty in the economics of catastrophic climate change'. Weitzman argues that there are large uncertainties associated with the probability of extreme events as projected by climate models as well as deep structural uncertainties related to economic risk evaluations, including damage cost estimates, discounting, and risk aversion. The latter are key issues in terms of real-life decision making, i.e. how much society should be willing to pay for adaptation in a given future climate scenario, which is often overlooked or severely simplified in many real-life climate change impact assessments. In this study we address the propagation of uncertainties and test critical assumptions in relation to a case study of urban flooding. Through a combination of climate scenarios, urban flood modelling, and economic assumptions, we analyse a total of 32 alternative scenario combinations, highlighting the role of key drivers and economic consequences.

\section{METHODOLOGICAL FRAMEWORK}

Seen from the perspective of a climate change adaptation decision maker, society should be willing to pay adaptation costs, which are at least equal to the avoided costs of climate change impacts. Adaptation costs should be adjusted for residual damages, up to the point where adaptation costs exceed residual costs. According to this, residual damages are associated with climate change impacts which either have very low damage costs or where adaptation is very expensive.

The avoided costs of climate change in terms of risks depend on damages as well as on the probability of a given event ${ }^{\underline{2}}$. Adhering to conventional usage of the term, we define climate change risks as the probability $\times$ consequence of a climate change event. For high consequence events with low probabilities, the estimated risks will depend on a sort of 'race' between how fast the probabilities of climate events decline, compared with how fast damage costs increase, when we are moving further away from the mean (median) of a climate probability density function.

Climate change impact assessment, e.g. as described by the traditional uncertainty cascade (e.g. Wilby \& Dessai 2010), generally involves integrated climate modelling and impact assessment. Specifically, future climate events such as temperature and precipitation extremes, wind storms, droughts, or combinations of these are used as drivers for impact assessments. Subsequently, economic consequence studies address damages to specific sectors, ecosystems, geographical locations, and human assets.

In the present study, damage costs are based on a bottom-up assessment, where cost parameters are assigned to different assets which are expected to be at risk from pluvial flooding; however, the approach could be easily generalized to other types of high impact events. Here assets include buildings, historical values, health, infrastructure, and ecosystems. The costs associated with damages to these assets are transformed to a measure of 'willingness-to-pay' (WTP) reflecting welfare loss, where risk aversion and equity concerns (given by alternative discount rates) are taken into consideration.

Fig. 1 illustrates the different logical steps of the impact assessment. Generally, in terms of describing the risks associated with a specific combination of one or more climate variables like temperature, precipitation, wind or sea level, the probability of a specific (possible compound) event is derived from climate projections. The probability may be expressed

\footnotetext{
${ }^{2}$ A climate event should here be understood as a broad terminology covering particular weather events like hot spells, intensive precipitation, wind storms, etc., which are associated with societal risks
} 


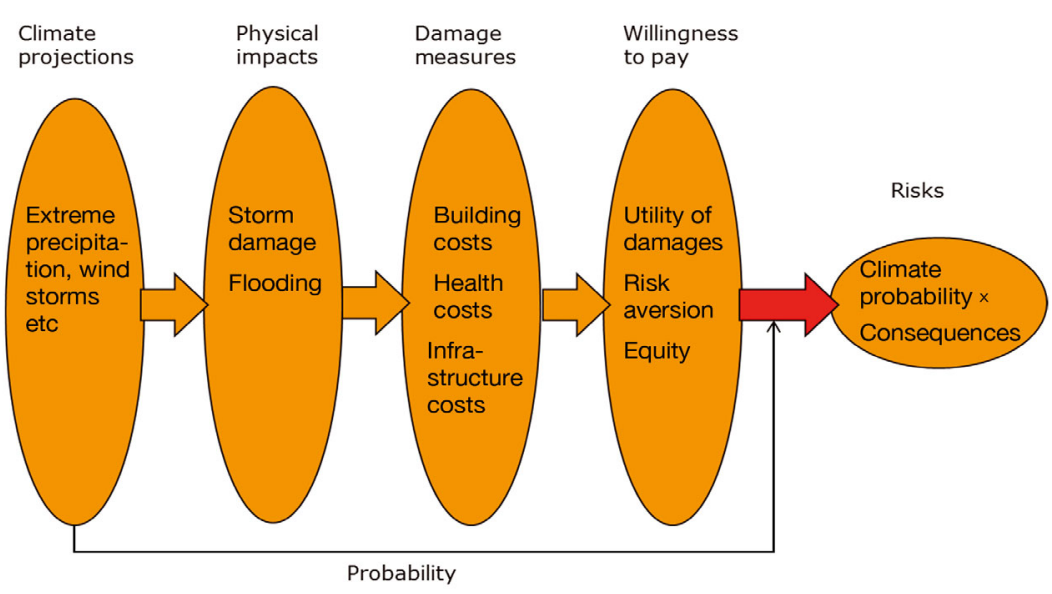

Fig. 1. Example structure of climate change impact assessment and risk analysis. The red arrow shows that the first and last step in the assessment are combined mate model projections, whereas the tails of the pdfs expresses (extreme) values further and further away from the mean. As shown in Fig. 2 the tails of the 2 pdfs differ significantly in their 'fatness'. While the 'thin-tailed' pdf is heavily centred and symmetric around the mean, the red 'fat-tailed' pdf is somewhat skewed and lends higher probability to extremes.

The thin- and fat-tailed distributions could be derived in different ways. One could think of the 2 distributions as being derived from 2 different ensembles of model simulations, e.g. forced by different climate scenarios (a moderate scenario like RCP4.5 versus a high sce- in the form of a probability density function (pdf), which is typically constructed on the basis of an ensemble of climate models. Principally, the pdf provides a comprehensive description with respect to both frequency and intensity. In practical terms it is far from trivial to construct such a pdf, especially for compound situations where more than one climate variable is involved. Hence, in some cases, more stylized shapes of pdfs are therefore used, e.g. in order to explore the tails of the distribution given certain assumptions about uncertainties (Weitzman 2011).

To exemplify, consider the 2 stylized pdfs illustrated in Fig. 2. The $x$-axis shows the change in the (anomaly) value of some climate variable, e.g. daily mean temperature, for a future time period with respect to a set control period; the $y$-axis expresses the probability of this value, e.g. as inferred from single model simulations or an ensemble of climate model projections. In this idealized example both distributions depict a nearly identical central value of an increase in daily mean temperature of $6^{\circ} \mathrm{C}$, which could be interpreted as the mean (median) of the cli-

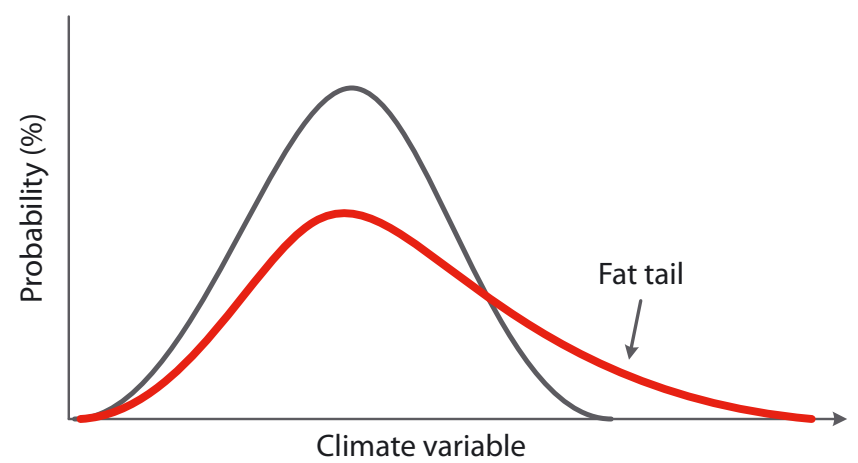

Fig. 2. Stylized representation of 2 alternative climate variable distributions nario like RCP8.5). For some geographical locations and for some variables like temperature and precipitation extremes many authors (e.g. Christensen \& Christensen 2003, Collins et al. 2012) have thus demonstrated that the probabilities of what are considered extremes under present-day conditions are likely to increase significantly under gradually higher levels of global warming. This implies that the tails corresponding to the higher end range of climate scenarios are similarly likely to be relatively 'fat'. Distributions could also be derived from the same ensemble using different methodologies and/or assumptions, or in the case of single or few model simulations, they could be based on entirely different climate models; hence, the difference primarily represents model uncertainty. It could also be a combination of all of the above. Either way, the impact assessment of an extreme event is likely to be heavily compound on the shape of this pdf, which of course introduces a significant uncertainty in terms of determining and quantifying risks.

The perspective of the damage cost assessment in our approach is social welfare ${ }^{3}$, where the total damage costs is an aggregate measure of the costs to all individuals of damages to given assets, and total damages are calculated as the sum of damages in all sub categories.

In terms of climate change, the uncertainty surrounding future events and the specific character of extreme events with low probabilities and high consequences suggests that the social welfare function applied to damage cost evaluation is adjusted to reflect society's perspective on uncertain future risks (Heal \& Kriström 2002, Weitzmann 2011). One way to

\footnotetext{
${ }^{3}$ Social welfare reflects society's perspectives as for example in relation to climate change impacts
} 
include this type of uncertainty in economic analysis is to apply a risk aversion factor. Risk aversion by definition is the reluctance of a person to accept a bargain with an uncertain payoff rather than a bargain with a certain payoff, and as already pointed out, extreme consequences of, for example, high-end climate scenarios are by their very nature uncertain.

As a basis for measuring WTP and following IPCC (Kolstad et al. 2014) we assume a social welfare function $(V)$, where $u\left(c_{t}\right)=V_{t}$ is the contribution to the social welfare function of generation $t$ consuming $C_{t}$. Since $c_{t}$ is uncertain, we consider the expected value $E u\left(c_{t}\right)$ of consumption in our social welfare function. The concavity of the function $u$ combines inequality aversion reflected in discount rate and risk aversion to reflect uncertainty:

$$
V=\sum_{t=0}^{\infty} E u\left(c_{t}\right) d(t)
$$

The factor $d(t)$ is a discount factor, which reflects equity in terms of our collective pure time preference for the present versus the future and an ethical parameter reflecting equity among present generations following the prescriptive approach to discounting reflecting equity concerns (IPCC 2014, section 3.6.2 therein).

We assume a risk aversion factor as defined by Arrow (1965):

$$
A(v)=-U^{\prime \prime}(\mathrm{v}) / U^{\prime}(v)
$$

where $A(v)$ is the risk aversion associated with a given social welfare change, and the utility of the social welfare change is:

$$
U(v)=\sum_{t=0}^{\infty} u\left(c_{t}\right)
$$

where $U^{\prime}(v)$ and $U^{\prime \prime}(v)$ are the first and second order derivatives of $U(V)$, respectively.

In the case of a utility function, which is a polynomial of order $n$, the form of the risk aversion factor reduces to the expression:

$$
A(v)=n C^{n-1}
$$

Hence the risk aversion is a constant. There are to the authors' knowledge no specific climate change risk attitude studies suggesting what the level of risk aversion should be, so instead we consider 2 different risk aversion factors (i.e. high and low risk aversion) based on an approach developed by Heal \& Kriström (2002), who suggest to use risk aversion values between 1 and 6 based on risk preferences revealed among investors.

The risks of climate change impacts may now be calculated from:
Risks $=$ WTP to avoid event $\times$ probability of event

$\mathrm{WTP}=$ damage costs $\times$ risk aversion factor

To exemplify how uncertainties and economic assumptions individually and combined influence risk levels, we apply the methodological framework to assess flood risks due to very high intensity rainfall in Odense.

\section{PLUVIAL FLOOD RISKS IN THE CITY OF ODENSE}

Odense is the largest city on Funen and the thirdlargest city in Denmark. It has 172 000 inhabitants and is an eclectic mix of residential housing, enterprises, industry, recreational areas, historical buildings, etc. The city is located next to Odense Stream and close to Odense Fjord, thus making the city centre vulnerable to different kinds of flooding. Recently, the risk of flooding due to heavy rainfall was assessed by the local government as the first step in a large decision-making framework aimed at developing a detailed climate change adaptation strategy and action plan ${ }^{4}$ (Odense kommune 2014, pers. comm.).

To identify major risk drivers and illustrate the role of uncertainties as well as the importance of climate scenario assumptions, damage cost functions, risk aversion, and discount rates we carry out a sensitivity analysis, constructing all possible combinations of these factors (illustrated in Fig. 3). Moving radially out from the centre of the circle, our starting point is the choice of climate scenario. The next step is to combine the climate scenario with 2 different damage assessment approaches. We then apply risk aversion factors of 3 and 1, respectively, where a factor of 1 implies risk neutrality, i.e. cost estimates are not adjusted by the risk perception. The factor of 3 represents a 'middle-of-the-road' perspective often favoured by real-life decision makers, effectively 'averaging' risks across a range of different (replaceable as well as irreplaceable) assets. Finally, the alternatives are transformed to levelized costs using a (moderate) $3 \%$ or a (low) $1 \%$ discount rate for a total of 32 combinations. It is evident that the levelized costs are inherently dependent on all parameters in this analysis, e.g. a higher level of risk aversion increases the levelized costs.

\footnotetext{
${ }^{4}$ All Danish local governments are obliged to develop local adaptation plans, which in the first phase until the end of 2014 are focussing on flood risks
} 


\subsection{Data}

The following physical and socio-economic data are used in the assessments:

- Downscaled climate projections from ArnbjergNielsen et al. (2015, this Special)

- Flood maps for Odense based on urban flood modelling using MIKE Urban/MIKE Flood software (MIKE By DHI 2014), wherein the city's topography and urban drainage system is included; this was supplied by the municipality of Odense (Odense kommune 2014, pers. comm.)

- GIS land cover data for Odense from the Danish Ministry of the Environment (Miljøministeriet 2014)

- Damage cost estimates for roads, railways and irreplaceable assets from Odense kommune (2014, pers. comm.)

- Damage cost estimates for houses, basements and other buildings from Arnbjerg-Nielsen \& Fleischer (2009), Zhou et al. (2012) and Forsikring \& Pension (2014)

- Since no unit damage cost estimates exists for the service and industry sectors, these were estimated based on insurance claims (Forsikring \& Pension 2014). Likewise, unit damage costs for health and waterbodies were estimated from Zhou et al. (2012).

\subsection{Climate projections}

Heavy rainfall intensities corresponding to 3 different climate scenarios as well as present day conditions have been reported by Christensen et al. (2015) and Arnbjerg-Nielsen et al. (2015). The first 2 scenarios were inferred from regional climate projections of the RCP4.5 and RCP8.5 scenarios for the period 2071-2100 and correspond to a global mean surface warming at the end of the 21st century of $\sim 2^{\circ} \mathrm{C}$ and $4^{\circ} \mathrm{C}$. Conversely, the last scenario represents an arbitrary future $30 \mathrm{yr}$ time slice, where a global mean surface warming of $6^{\circ} \mathrm{C}$ is realized (Christensen et al. 2015). Based on the 3 time slices we calculate the annual probability of rainfall events of a particular intensity for the different climate scenarios (Fig. 4).

For the scenarios associated with the higher global mean temperature changes, the probability of specific high intensity rainfall events is clearly seen to increase relatively, as do the maximum intensities. This implies that if we consider the frequency of specific events then the distributions derived from the higher end scenarios are effectively 'fat-tailed' as compared to the 'thin-tailed' distributions derived from lower scenarios or present-day conditions (Fig. 2).

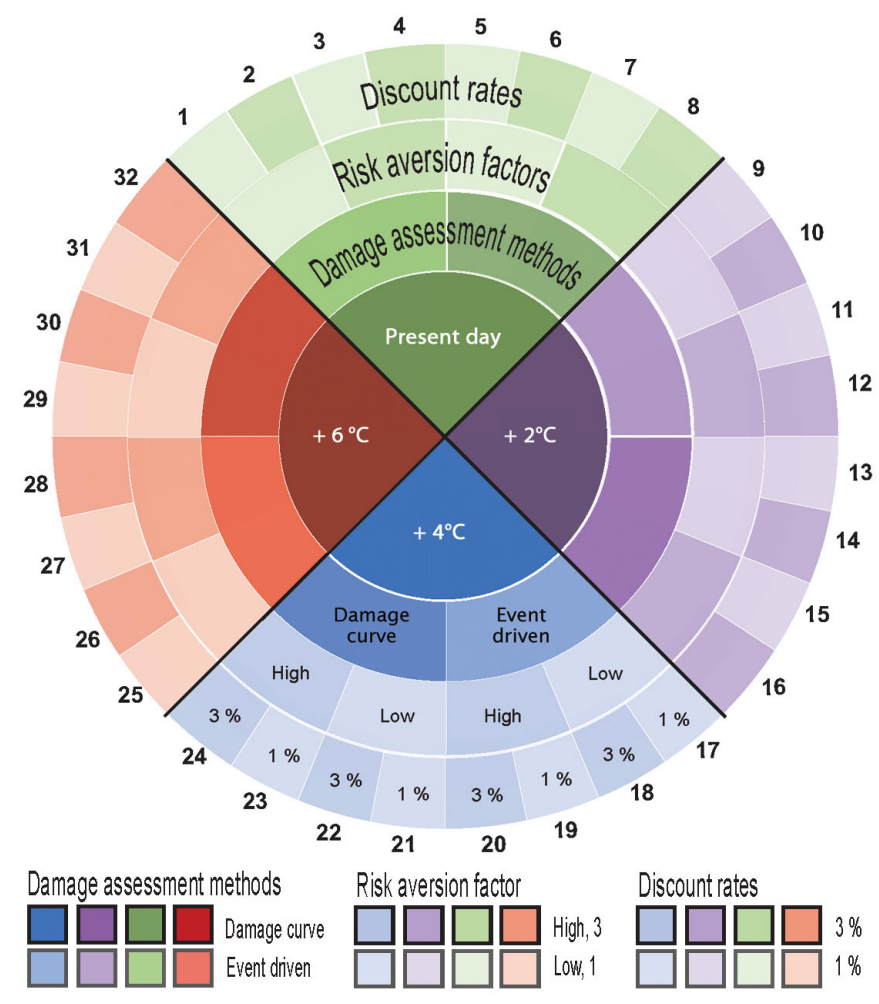

Fig. 3. Structure of a sensitivity analysis applied to the pluvial flooding case; 32 different scenario combinations are shown

Evidently, this is not the whole story, since both global and regional climate projections are influenced by a wide range of further uncertainties, including bias, model uncertainty and internal variability, whose relative importance varies with prediction lead time and with spatial and temporal averaging scale (e.g. Hawkins \& Sutton 2009, 2011). Similarly, empirical-statistical downscaling of precipitation is also affected by considerable uncertainties and critical assumptions (Sunyer et al. 2014). In this study, as in many real-life impact assessments, we do not have sufficient information to strictly decompose the variance of the climate projections. For simplicity we instead use the full range of climate scenarios discussed above as sort of a proxy for assigning specific probabilities to specific precipitation intensities across scenarios. In general for precipitation Hawkins \& Sutton (2011) identify model uncertainty as the predominant source of uncertainty more or less independently of lead time, which suggests that the climate uncertainty used in this analysis may be deflated. Recent work by Gregersen et al. (2014) on the other hand finds that the spread of the projections for Denmark used herein exceeds the observed spread in a comparable ensemble of regional climate projections 
from ENSEMBLES (van der Linden \& Mitchell 2009), indicating that in this specific case the scenario uncertainty may at least to the 0th order be considered to be representative of the total climate uncertainty.

Another important point to consider in the perspective of decision making on climate change adaptation is the issue of time and learning, e.g. what happens when the focus moves from low-end climate scenarios with possible moderate impacts to higher-end scenarios with more severe impacts. Since decisions about adaptation measures typically will have a much shorter time perspective than developments in the climate system, it is important to consider the timing of when risks associated with different climate scenarios actually can materialise and when given adaptation is necessary. One way to reflect the time perspective is to compare the time frame determined by different climate models of when alternative global mean temperature changes can emerge. Comparing the global annual mean temperature projections for the RCP8.5 scenario of 38 CMIP5 (Taylor et al. 2012) members compared to the pre-industrial 1881-1910 period, Christensen et al. (2015) for example showed that around the year 2100 is the 'earliest' time when

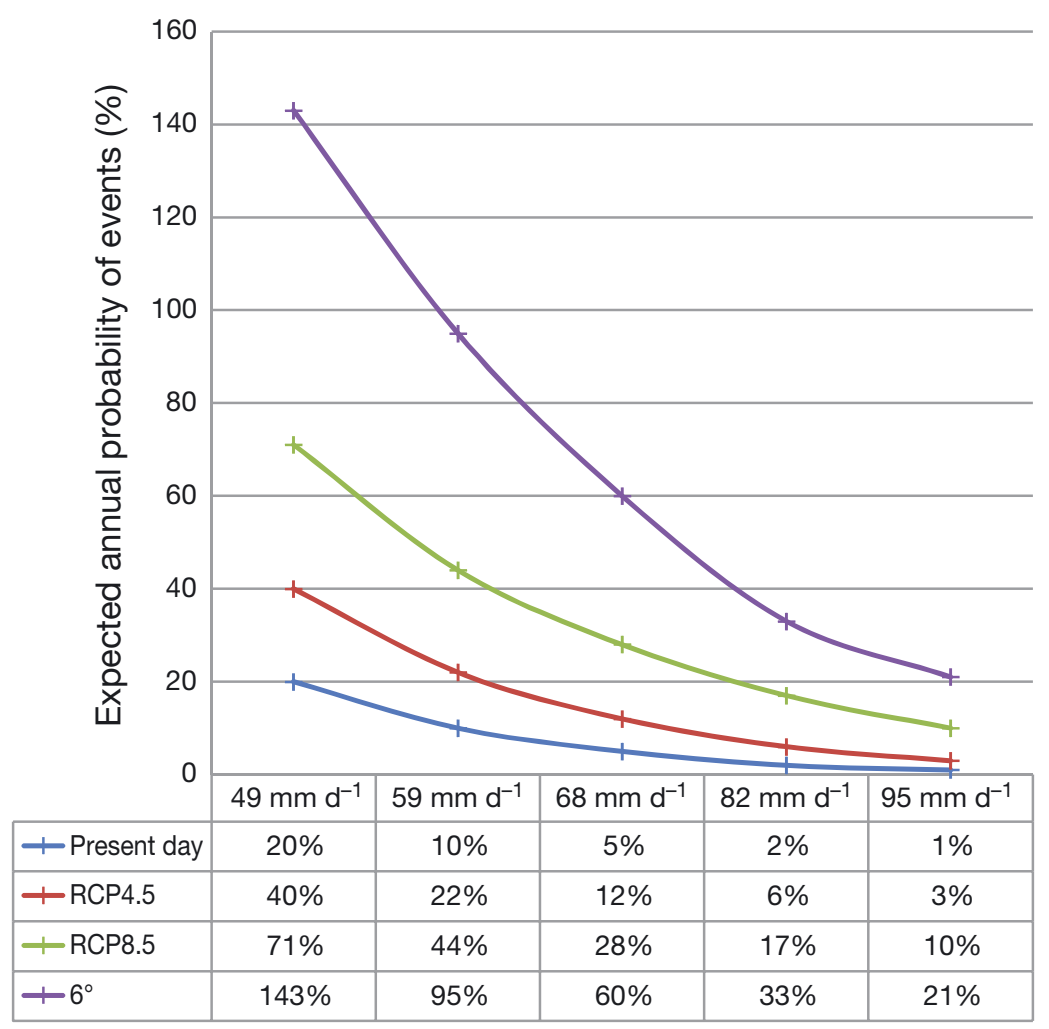

Fig. 4. Expected annual probability of intense precipitation events for the different climate scenarios: present day, regional climate projections (RCP) RCP4.5 and RCP8.5, and $6{ }^{\circ} \mathrm{C}$ increase a $6^{\circ} \mathrm{C}$ global mean temperature change could be achieved. Conversely, the same study finds that most of the projections achieve $6^{\circ} \mathrm{C}$ before 2130 . It is evident that adapting to such high temperature levels will not be needed until far into the future. If we are instead to consider high-end scenarios within the time frame of the 22nd century, it makes sense to focus on the risks associated with moving from a $4^{\circ} \mathrm{C}$ scenario to a $6^{\circ} \mathrm{C}$ scenario rather than only focusing on the highest climate scenario.

\subsection{Flooded assets}

To estimate the damage costs we combine detailed modelling of the topography and the urban drainage system with geographical information in a GIS format. The geographical information includes data on vulnerable assets in terms of buildings, roads, railways, cultural and historical values, ecosystems, and human health, and is based on a static picture of present day city activities and structure. State-of-theart maps describing the likely location and extent of flooding following alternative extreme precipitation events have recently been produced for Odense using the MIKE Urban/MIKE Flood (MIKE By DHI 2014) modelling tools. For some assets like damage cost estimates of buildings in this assessment step are based on very aggregate general categories of private houses and commercial buildings. Urban ecosystems or recreational areas are not included in the assessment, and neither is discomfort to people due to stress associated with the event or loss of working hours for cleaning up after the flooding. Both of these could potentially be associated with significant costs. The same is the case with losses associated with disruptions in industrial activities and business, which have not been taken into consideration because only very small-scale industrial activities are located in the central city of Odense. Flooding would therefore not have a large economic impact on these activities. Similarly, losses in business activities and shopping are not included, which like in the case of industrial activities could tend to cause an underestimation of damage costs. It could however be expected that many business and shopping activities would be postponed for a few days due to flooding, and that economic losses thereby would be small. 
It could be argued that basing our damage cost assessment on a static picture of the city would tend to underestimate costs because the value of damaged assets would increase over time. This will certainly be the case, but there is currently no good methodology available that can be used to make a detailed projection of city activities, which can merge the details in our flooding calculations. The present study uses location-specific information about houses, roads and other assets, and we cannot project these. A possibility could be to add a general factor to reflect increases in the value of city assets over time, and this would in general work as a multiplier on the costs and thereby increase the damage estimates. We have chosen not to do this because the major point of our study is not to provide accurate cost estimates, but rather through a sensitivity analysis to demonstrate the importance of key economic assumptions. We are not really expecting high population growth in Danish cities, but the value of assets would increase if the current trend of city development continues.

The total number of buildings and other assets likely to be affected by different flooding events in Odense are compiled in Table 1.

We note from Table 1 that the total number of buildings and basements flooded is clearly increasing with increasing precipitation intensities (maximum event intensities). The same is the case for roads, railways, etc. In the case of health impacts and irreplaceable assets such as historical buildings, a particularly high number of incidences are seen to appear for precipitation events exceeding a threshold of $30 \mathrm{~mm} \mathrm{~h}^{-1}$.

\subsection{Damage cost approach}

Damage cost estimates are based on a number of different data sources, implying that unit cost data for different assets may be uncertain. Unit cost data have been adjusted to common measurement standards (Tables A1 \& A2 in the Appendix).

The damage cost assessments are based on 2 alternative methods to exemplify differences in reallife damage assessments. In the traditional 'damage curve' (DC) approach, the modelled surface water depth is used directly as a measure of severity. Using the DC approach, damage costs per asset flooded increases linearly as the water depth increases, until it reaches a predefined level, where it is assumed that maximum possible damages occur (Table A1 in the Appendix). This water depth by assumption varies between assets and is set to be 50 to $70 \mathrm{~cm}$ in the present study. The selected water levels for maximum damage were based on European and American findings in accordance with Jongman et al. (2012) and Davis \& Skaggs (1992).

Table 1. Flooded assets for rainfall events with different intensities. For simplicity, buildings and basements are treated as uniform categories

\begin{tabular}{|c|c|c|c|c|c|c|c|}
\hline \multirow{2}{*}{ Flooded assets } & \multirow{2}{*}{$\begin{array}{l}\text { Water depth flooding } \\
\text { threshold }(\mathrm{cm})\end{array}$} & \multirow[b]{2}{*}{20} & \multirow{2}{*}{\multicolumn{4}{|c|}{ Event intensity $\left(\mathrm{mm} \mathrm{h}^{-1}\right)-$}} & \multirow{2}{*}{ Unit } \\
\hline & & & 25 & 30 & & 40 & \\
\hline \multicolumn{8}{|l|}{ Buildings } \\
\hline Service and Industry & 20 & 59 & 94 & 174 & 231 & 278 & No. of buildings \\
\hline Multistorage residential & 20 & 38 & 56 & 95 & 103 & 123 & \\
\hline Houses & 20 & 87 & 201 & 398 & 472 & 576 & \\
\hline Leisure house & 20 & 108 & 229 & 419 & 490 & 605 & \\
\hline Basements & 5 & 178 & 311 & 573 & 569 & 726 & No. of basements \\
\hline $\begin{array}{l}\text { Health effects from } \\
\text { basement flooding }\end{array}$ & 0.3 & 475 & 757 & 1356 & 1397 & 1659 & No. of people affected \\
\hline Roads & 5 & 120 & 212 & 374 & 434 & 533 & $1000 \mathrm{~m}^{2}$ \\
\hline Railways & 5 & 2 & 5 & 9 & 12 & 15 & $1000 \mathrm{~m}^{2}$ \\
\hline $\begin{array}{l}\text { Waterbodies flooded in } \\
\text { the city with mixed surface } \\
\text { and sewage water }\end{array}$ & 20 & 29 & 31 & 41 & 43 & 46 & No. of waterbodies \\
\hline \multicolumn{8}{|l|}{ Irreplaceable assets } \\
\hline Ancient monuments & 20 & - & - & 1 & 2 & 2 & Buildings \\
\hline Churches & 20 & - & - & 1 & 1 & 1 & Buildings \\
\hline Conservation worthy buildings & 20 & 10 & 22 & 58 & 60 & 74 & Buildings \\
\hline Clergy buildings middle age & 20 & - & - & - & - & - & Buildings \\
\hline Statues and sculptures & 20 & 2 & 2 & 5 & 5 & 7 & Buildings \\
\hline Museums & 20 & - & - & 4 & 4 & 5 & Buildings \\
\hline
\end{tabular}


In the 'event-driven' (ED) approach, unit damage cost is kept constant for all water levels exceeding a certain water depth threshold. As assets have different susceptibility towards the water level required to cause damages, a water depth threshold is defined for each asset type to represent a given asset damage cost, and this threshold is constant for all precipitation events (see Table A2). Damage unit costs are related to the intensity and total amount of precipitation during a precipitation event. As the intensity of the precipitation events increases so does the total number of assets flooded and the unit cost per damage. The logic behind this approach is that the likelihood of assets being flooded with water levels above the defined threshold increases with the amount of precipitation increase. This relationship has been confirmed by available data for insurance claims from flooding during high-intensity precipitation events in Denmark in the period 20062013 (Forsikring \& Pension 2014), where it can be seen that the average insurance claim was 3 to 10 times higher for damages from high-intensity precipitation events compared with low-intensity precipitation events.

As shown in Fig. 5 the range of damage costs span from about 17 million EUR for the smallest precipitation event, to over 300 million EUR for the most intensive event. Cost estimates derived using the ED approach start below the DC cost level, but increase more steeply and pass the DC based costs for precipitation events of more than $30 \mathrm{~mm} \mathrm{~h}^{-1}$. This implies that using the ED approach will generate higher risk

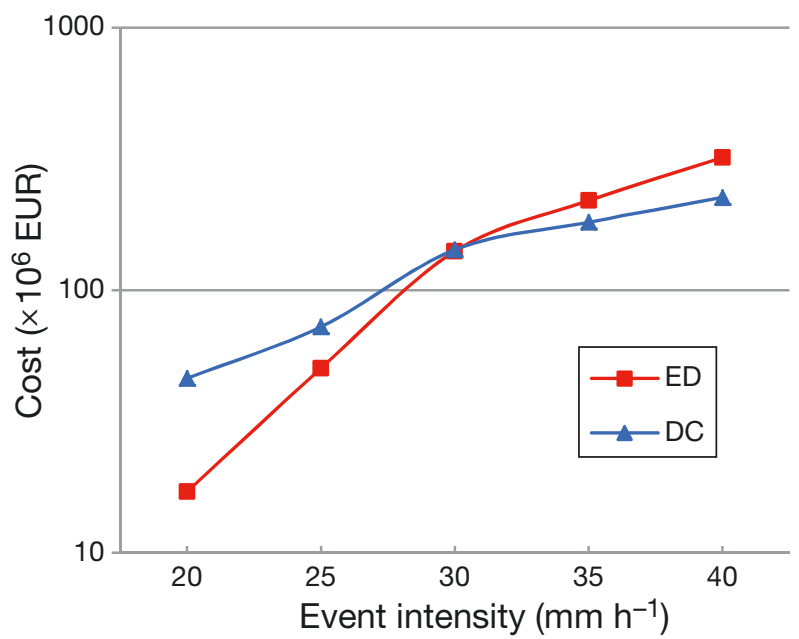

Fig. 5. Estimated total damage costs due to high-intensity precipitation events in Odense, Denmark, using the damage curve (DC) and event-driven (ED) approach

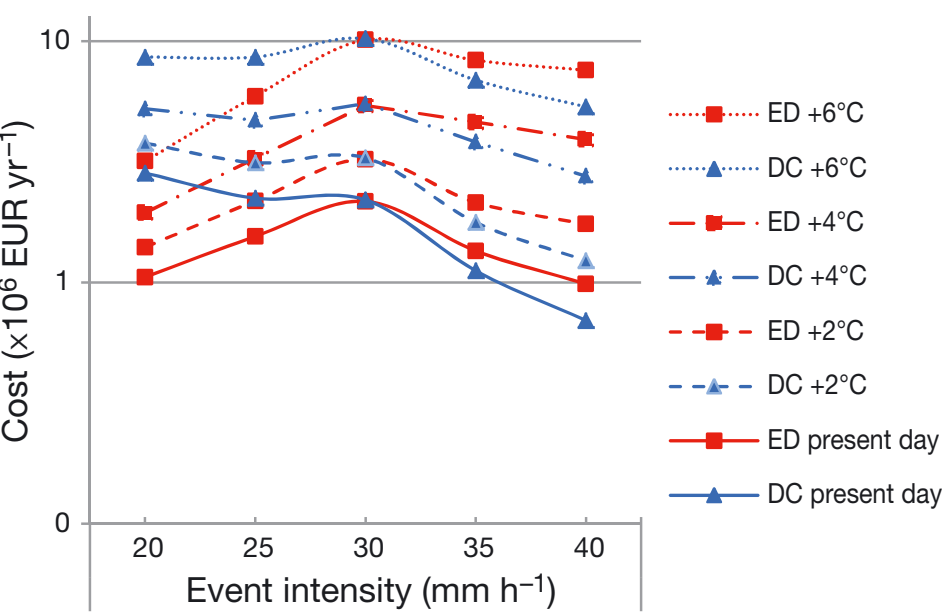

Fig. 6. Levelized costs of flood damage over a $100 \mathrm{yr}$ period for different climate change scenarios $\left(+2^{\circ},+4^{\circ}\right.$, and $\left.+6^{\circ} \mathrm{C}\right)$ using a $3 \%$ discount rate. ED: event-driven, DC: damage curve

estimates for very intense precipitation, which may be more likely in higher-end climate scenarios. It is important to recognize here that both approaches depend on the availability of reliable damage cost data, and that such data in most real-life cases is likely to be sparse. Likewise, both approaches ignore the indirect costs of pluvial flooding, which in absolute terms may be considerable, but which for the purpose of a sensitivity analysis makes them equally good (or bad).

The damage costs are transformed to risk estimates by multiplying the estimated costs with the probability of an event happening at a different point in time. From this we calculate net present values and corresponding levelized costs ${ }^{5}$. These risks are illustrated in Fig. 6 for alternative climate scenarios. The levelized costs of the damages are seen to increase for higher precipitation intensities in the ED approach, peaking at $30 \mathrm{~mm} \mathrm{~h}^{-1}$ precipitation. In the case of the $6^{\circ} \mathrm{C}$ scenario, levelized costs are 3 times higher than for the $2^{\circ} \mathrm{C}$ scenario. Furthermore, despite the lower inherent probability for very intensive precipitation events of $40 \mathrm{~mm} \mathrm{~h}^{-1}$ as compared to events of $30 \mathrm{~mm} \mathrm{~h}^{-1}$ levelized damages are almost at the same level in both cases under the ED approach. In the DC approach, where damages increase until a maximum threshold level, the levelized costs of the damages reach a maximum already at $20 \mathrm{~mm} \mathrm{~h}^{-1}$, after which they decrease faster than in the ED approach.

\footnotetext{
5The levelized costs are the net present value transformed to constant annual costs by integrating over a time frame of $100 \mathrm{yr}$
} 


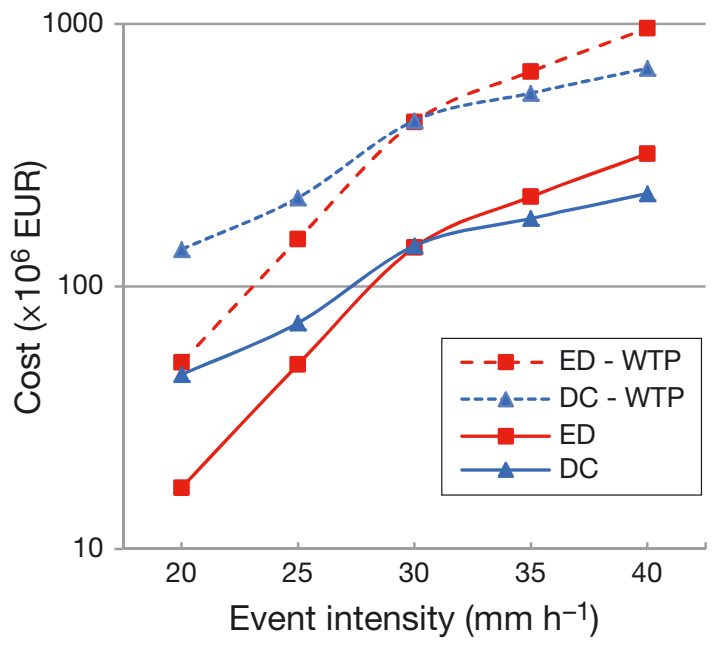

Fig. 7. Total damage costs during high-intensity precipitation events in Odense, Denmark. WTP (willingness-to-pay) = event-driven (ED) or damage curve (DC) costs with a risk aversion factor of 3

\subsection{Risk aversion and discount rates}

Adding a risk aversion factor as suggested by Weitzman (2011) to reflect people's attitudes towards risk will increase the costs (Fig. 7). We apply an absolute risk aversion factor of 3. In terms of WTP this also triples the costs, and the same upwards shift in costs is observed in the levelized costs.

Fig. 8 shows the levelized costs for the 2 damage functions under the $6^{\circ} \mathrm{C}$ scenario applying both a low $(1 \%)$ and a medium high $(3 \%)$ discount rate $^{6}$. Levelized costs are almost 3 times higher again, depending on a 1 versus a $3 \%$ discount rate.

In this way the actual level of risks associated with flooding from extreme precipitation in Odense can vary significantly depending in near equal parts on climate scenario assumptions, damage cost approach, and cost assumptions. The importance of these factors is assessed systematically in the next section.

\subsection{Sensitivity analysis}

The risks measured as levelized costs for all the 32 scenario combinations are shown in Fig. 9. The costs for the lowest and the

${ }^{6}$ Discount rates between 1 and up to $6 \%$ have been suggested for climate change costing studies based on different theoretical arguments; See Arrow et al. (1996) for a detailed discussion

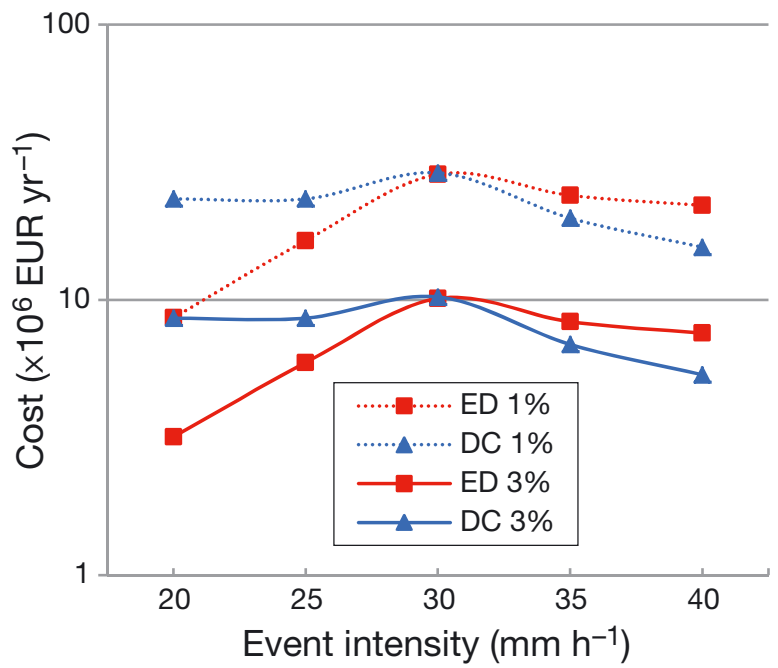

Fig. 8. Levelized costs of flood damage over a $100 \mathrm{yr}$ period under a $6^{\circ} \mathrm{C}$ scenario and discount rates of 1 and $3 \%$ under the damage curve (DC) and event-driven (ED) approach

highest risks vary from about 85 million EUR down to less than 1 million EUR. In terms of decision making, it is however important to notice that most of the combinations of economic assumptions and climate scenarios assess the risk to be between 7 and 30 million EUR $\mathrm{yr}^{-1}$, while only 4 out of the 32 combinations really stand out and go far beyond a 30 million EUR $\mathrm{yr}^{-1}$ risk level. The high risk cases exclusively correspond to the high-end 4 and $6^{\circ} \mathrm{C}$ climate scenarios, a risk aversion factor of 3 and a low discount rate of $1 \%$.

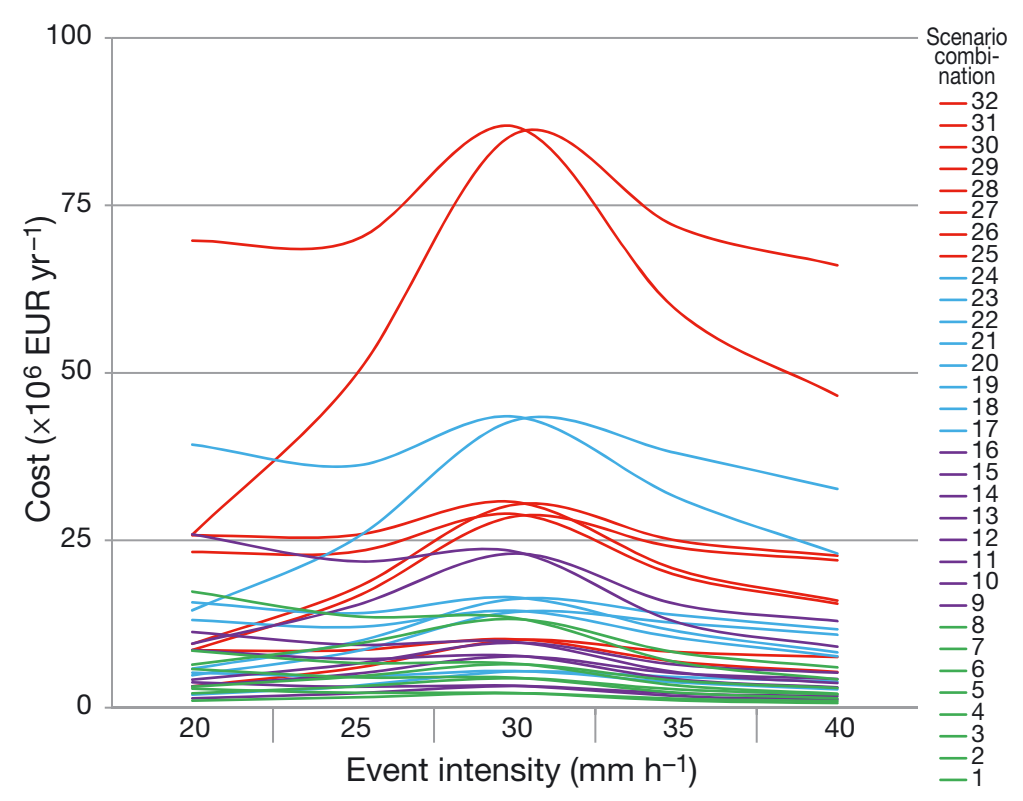

Fig. 9. Risks represented by levelized costs over a 100 yr period calculated for all 32 scenario combinations (see Fig. 3 ). Red: $+6^{\circ}$, blue: $+4^{\circ}$, and purple: $+2^{\circ} \mathrm{C}$ climate scenario combinations; green $=$ present day 
The wide range of risk estimates as presented in Fig. 9 is a result of a combination of climate scenarios and economic assumptions; below we separately examine the importance of these 2 set of assumptions in order to further shed light on key uncertainties. Starting with the climate scenarios, Fig. 10 shows the range of risk estimates by scenario. It is here clear that going beyond a $2^{\circ} \mathrm{C}$ climate scenario has large implications on risk estimates.

As previously stated, it is important from a decision-making point of view to consider the magnitude and uncertainties of damage estimates when we move from, for example, a $2{ }^{\circ} \mathrm{C}$ to higher end scenarios, and timing here is important in relation to planning perspectives of adaptation. Recent climate simulations suggest that a $4^{\circ} \mathrm{C}$ increase could be achieved already around 2050 if current high GHG emission pathways continue. Hence depending on the timeframe of the actual adaptation considered, it may be highly relevant, within a timeframe of up to 2100 , to assess options in the context of risks when moving from a $4^{\circ} \mathrm{C}$ scenario to a $6^{\circ} \mathrm{C}$ scenario.

Applying alternative economic assumptions to the damage cost assessment expands the range of risk assessment for the climate scenarios. We further examine the role of the economic assumptions keeping the climate scenario constant at the $6^{\circ} \mathrm{C}$ level. As exemplified in Fig. 11, the choice of discount rate and risk aversion factor can both have a high impact on risk levels. For example, for a precipitation intensity of $30 \mathrm{~mm} \mathrm{~h}^{-1}$ the risks are found to vary between $\sim 10$ and 85 million EUR. Moreover, given the assumptions we have applied in this case study, a combination of high risk aversion and high discount rate actually yields the same results as a combination of low risk aversion and low discount

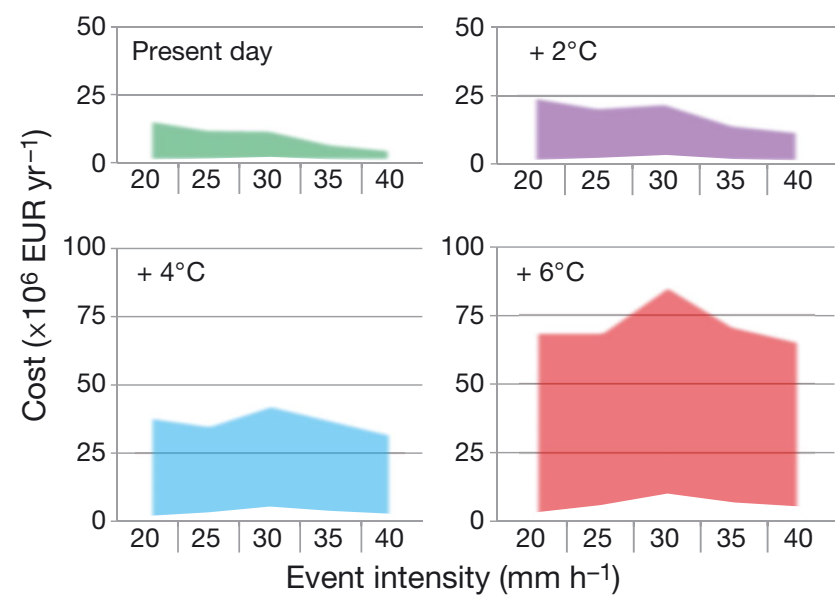

Fig. 10. Range of levelized costs given different climate scenarios and precipitation levels

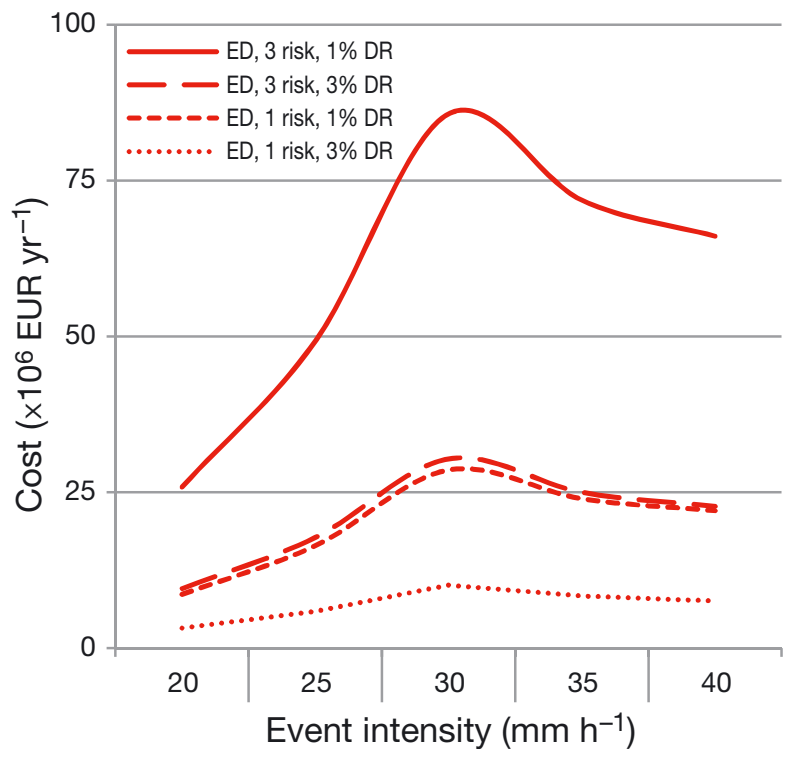

Fig. 11. Levelized costs of risks for the $6^{\circ} \mathrm{C}$ scenario with risk aversion factors 1 and 3 (risk), and 1 and $3 \%$ discount rates (DR)

rate. This is a coincidence based on the choice of assumptions. From Fig. 11 only the combinations of a high risk aversion factor and a low $1 \%$ discount rate result in risks above the 30 million EUR $\mathrm{yr}^{-1}$ level, which as previously stated is the maximum level for most of the scenario combinations that are included in the full range of the sensitivity analysis as shown in Fig. 9.

In conclusion it can be said that the alternative climate scenarios, as included in Fig. 10, show a variability of the risk estimates from $\sim 15$ million EUR $\mathrm{yr}^{-1}$ as the highest estimate for the $2^{\circ} \mathrm{C}$ scenario to about 80 million EUR $\mathrm{yr}^{-1}$ for the $6^{\circ} \mathrm{C}$ scenario. Keeping the

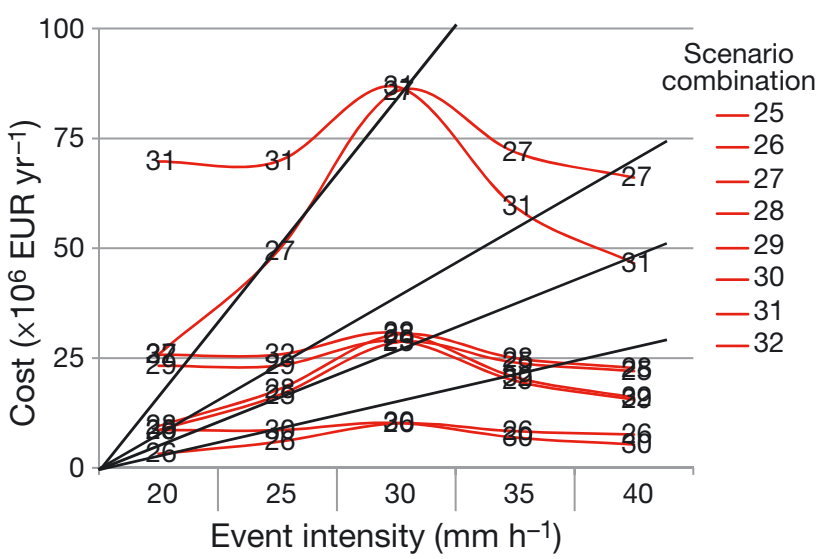

Fig. 12. Levelized climate risks and stylized climate risk reduction curves by adaptation for the $6^{\circ} \mathrm{C}$ climate scenario. Scenario numbers: from the 32 combinations in Fig. 3 


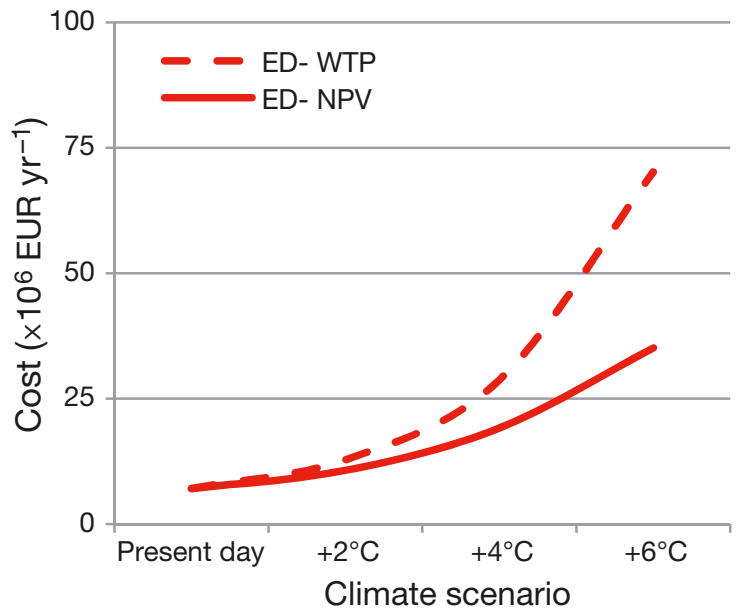

Fig. 13. Levelized costs for different climate scenarios using the event-driven (ED) damage assessment method. The risk aversion factor increases from 1 to 2 as climate change increases in the willingness-to-pay (WTP) measure, with a $3 \%$ discount rate. NPV: net present values

$6^{\circ} \mathrm{C}$ scenario constant and then alternatively varying the economic assumptions on risk aversion and discount rate as shown in Fig. 11 provides an almost similar range of risk estimates; so given our assumptions it can be concluded that the set of climate scenarios and economic assumptions influence the risk estimates in a very similar way.

\section{DISCUSSION}

In the present study we frame climate change risk assessments in terms of how much society should be willing to invest in adaptation measures based on willingness-to-pay measures. The focus here is on a local geographical area, defined by specific climate change risks as exemplified by the case study discussed in the previous sections. Since decision makers in a local context cannot through their own adaptation actions influence atmospheric GHG concentrations significantly, we can assume that they have to consider, at a given point in time, climate change scenarios as a reality. In this construction of the decision-making issues, it is relevant to compare the costs of adaptation with the risk reduction achieved by adaptation assuming that a given climate scenario is emerging. The objective function for decision making can then be formulated as:

$$
\begin{aligned}
& \text { Climate risks = adaptation costs }+ \\
& \text { residual damages after adaptation }
\end{aligned}
$$

where the right-hand side of the equation represents climate risk reductions by adaptation. Residual dam- ages are included in the calculation in order to reflect that the costs of adaptation at some point can increase to a level where the benefit of risk reduction by adaptation is smaller than the costs. Using the same format as in Fig. 9, picturing the risk of all 32 scenario combinations, the decision-making issue for a given climate scenario objective, e.g. a $6^{\circ} \mathrm{C}$ scenario, could be as illustrated in Fig. 12. Adaptation costs should be less than or equal to the avoided damages (represented by the risk curves), and the decision maker can then compare adaptation cost curves with the risk curves. When adaptation costs intersect the risk curves, the benefit of implementing adaptation to protect against a high event intensity level is less than the adaptation costs. The straight lines exemplify stylized alternatives of climate risk reduction curves by adaptation and are merely for illustrative purposes.

The recommended risk management levels will of course depend on the exact shape of the adaptation cost and residual damage curves, which were not estimated in this study. As drawn in Fig. 12 in most cases the optimal risk management level will be at a precipitation level of around $30 \mathrm{~mm} \mathrm{~h}^{-1}$. It is primarily with assumptions of high risk aversion and low discount rate that the recommended safety level exceeds this.

To put the decision-making perspective into a larger context, i.e. in terms of climate change mitigation perspectives, the risk reduction in terms of urban flooding can also be seen as a measure of the benefits of avoiding the consequences of alternative climate change scenarios. For illustrative purposes, Fig. 13 shows risk estimates for moving from no climate change to a $2^{\circ}, 4^{\circ}$, and $6^{\circ} \mathrm{C}$ climate change scenario. We assume here that the risk aversion factor applied to the willingness-to-pay assessment increases linearly from 1 to 2 when we are on a trajectory to a $6^{\circ} \mathrm{C}$ climate scenario. However, one might also argue for the risk aversion factor to increase with global mean temperature change due to ambiguity in relation to future uncertain high consequence events (Weitzmann 2011).

Confronting the climate change risk estimates with the mitigation issues illustrates that by considering different levels of temperature change, the risk function will be convex in shape, while adding a risk aversion factor, which is increasing with temperature, clearly results in a much faster increase in the risk curves. Applying similar assumptions in a global decision-making context would thus point to the conclusion that a more ambitious level of climate change mitigation should be implemented. 
That said, the actual shape of damage curves as well as risk aversion factors for different vulnerable assets will of course vary.

\section{CONCLUSIONS}

A methodological framework for integrated assessment of climate change impacts and welfare consequences has been developed and applied to a case study of urban flooding due to extreme precipitation in Odense. The approach distinguishes climate scenario uncertainties related to climate signals as such and to the probability of tail events with high consequences, while combining this information with alternative economic assumptions for damage functions, risk aversion, and equity as reflected in discount rates.

A systematic sensitivity analysis including 32 scenario combinations demonstrates that alternative climate scenario assumptions as well as economic assumptions together result in risk estimates with a very large variation. We find that a major source of uncertainty relates to the climate scenario uncertainty, in particular related to the probability of tail events associated with high consequences to society. The economic assumptions, particularly on risk aversion factor and discount rate, are both very important and contribute to a very large variation of risk estimates. Furthermore, the actual level of damage costs associated with different levels of precipitation intensity is important in determining the risk levels. The latter is a challenge to impact modellers, and the accuracy of damage cost studies could benefit from the availability of more context-specific studies on impacts on physical assets, human welfare, and risk perception, and on how the full range of economic activities in the city could be affected.

In the context of uncertainty and decision making, the results of the sensitivity analysis seen from a climate modelling perspective and from an economic perspective can be interpreted in different ways. Uncertainties related to the climate scenarios reflect both the state of current climate modelling and statistical downscaling approaches applied to the case study, as well as more general uncertainties related to global decision making on climate change mitigation and future temperature levels. In terms of adequately eliciting these uncertainties in an integrated framework, an ensemble of comprehensive model experiments, specifically designed to decompose the variance, which take into account key factors such as the scenario and model uncertainty is required. The uncertainties related to the economic estimates are more related to different theoretical concepts of risk aversion and discounting, and the sensitivity analysis illustrates what the consequences of these different uncertainties could be.

Acknowledgements. The present study was funded by a grant from the Danish Strategic Research Council for the Centre for Regional Change in the Earth System (CRES) under contract no: DSF-EnMi 09-066868. CRES is a multidisciplinary climate research platform, including key Danish stakeholders and practitioners with a need for improved climate information.

\section{LITERATURE CITED}

Arnbjerg-Nielsen K, Fleischer HS (2009) Feasible adaptation strategies for increased risk of flooding in cities due to climate change. Water Sci Technol 60:273-281

Arnbjerg-Nielsen K, Leonardsen L, Madsen H (2015) Evaluating adaptation options for urban flooding based on new high-end emission scenario regional climate model simulations. Clim Res 64:73-84

Arrow KJ (1965) The theory of risk aversion. In: Aspects of the theory of risk bearing, Yrjö Jahnssonin Säätiö, Helsinki. Reprinted in: Arrow KJ (1971) Essays in the theory of risk bearing, Markham, Chicago, IL, p 90-109

Arrow KJ, Cline WR, Maler KG, Munasighe M, Squitieri R, Stiglitz JE (1996) Intertemporal equity, discounting, and economic efficiency. In: Bruce JP, Lee H, Haites EF (eds) Climate change 1995: economic and social dimensions of climate change. Contribution of Working Group III to the Second Assessment Report of the Intergovernmental Panel on Climate Change, Cambridge University Press, Cambridge, p 127-144

Christensen JH, Christensen OB (2003) Severe summertime flooding in Europe. Nature 421:805-806

Christensen OB, Yang S, Boberg F, Fox Maule C and others (2015) Scalability of regional climate change in Europe for high-end scenarios. Clim Res 64:25-38

Collins M, Chandler RE, Cox PM, Huthnance JM, Rougier J, Stephenson DB (2012) Quantifying future climate change. Nat Clim Change 2:403-409

Davis SA, Skaggs LL (1992) Catalog of residential depthdamage functions used by the army corps of engineers in flood damage estimations. US Army Corps of Engineers, Institute for Water Resources Report 92-R-3, Springfield, VA

Forsikring \& Pension (Danish Insurance Association) (2014) Erstatning for vandskader. Available at www. forsikringogpension.dk/presse/Statistik_og_Analyse/ statistik/forsikring/erstatninger/Sider/Erstatninger_for_ vandskader.aspx (accessed 20 January 2014)

Gregersen IB, Madsen H, Linde JJ, Arnbjerg-Nielsen K (2014) Opdaterede klimafaktorer og dimensionsgivende regnintensiteter. Spildevandskomiteen, Skrift 30. Available at https://ida.dk/sites/prod.ida.dk/files/svk_skrift 30_0.pdf (accessed 20 March 2015)

Hawkins E, Sutton R (2009) The potential to narrow uncertainty in projections in regional climate predictions. Bull Am Meteorol Soc 90:1095-1107

Hawkins E, Sutton R (2011) The potential to narrow uncertainty in projections of regional precipitation change. Clim Dyn 37:407-418 
Heal G, Kriström B (2002) Uncertainty and climate change. Environ Resour Econ 22:3-39

IPCC (Intergovernmental Panel on Climate Change) (2005) Guidance notes for lead authors of the IPCC Fourth Assessment Report on addressing uncertainties. Available at www.ipcc-wg1.unibe.ch/publications/supportingmaterial/ uncertainty-guidance-note.pdf

IPCC (2012) Managing the risks of extreme events and disasters to advance climate change adaptation. In: Field CB, Barros V, Stocker TF, Qin D and others (eds) A Special Report of Working Groups I and II of the Intergovernmental Panel on Climate Change. Cambridge University Press, Cambridge, and New York, NY

IPCC (2013) Annex II: climate system scenario tables (Prather M, Flato G, Friedlingstein P, Jones C, Lamarque JF, Liao H, Rasch P [eds]). In: Stocker TF, Qin D, Plattner G-K, Tignor M and others (eds) Climate change 2013: the physical science basis. Contribution of Working Group I to the Fifth Assessment Report of the Intergovernmental Panel on Climate Change. Cambridge University Press, Cambridge, and New York, NY, p 1395-1445

Jongman B, Kreibich H, Apel H, Barredo JI and others (2012) Comparative flood damage model assessment: towards a European approach. Nat Hazards Earth Syst Sci 12:3733-3752

Kolstad C, Urama K, Broome J, Bruvoll A and others (2014) Social, economic and ethical concepts and methods. In: Edenhofer O, Pichs-Madruga R, Sokona Y, Farahani E and others (eds) Climate change 2014: mitigation of climate change. Contribution of Working Group III to the Fifth Assessment Report of the Intergovernmental Panel on Climate Change. Cambridge University Press, Cambridge, and New York, NY, p 207-282
Meinshausen M, Smith SJ, Calvin KV, Daniel JS and others (2011) The RCP greenhouse gas concentrations and their extension from 1765 to 2300. Clim Chang 109:213-241

MIKE By DHI (2014) www.MIKEbydhi.com (accessed 29 September 2014)

Miljøministeriet (Danish Ministry of the Environment) (2014) Kortforsyningen www.kortforsyningen.dk (accessed 15 November 2014)

Refsgaard JC, Arnbjerg-Nielsen K, Drews M, Halsnæes K and others (2013) The role of uncertainty in climate change adaptation strategies - a Danish water management example. Mitig Adapt Strategies Glob Change 18: 337-359

Sunyer MA, Hundecha Y, Lawrence D, Madsen H and others (2014) Inter-comparison of statistical downscaling methods for projection of extreme precipitation in Europe. Hydrol Earth Syst Sci Discuss 11:6167-6214

Taylor KE, Stouffer RJ, Meehl GA (2012) An overview of CMIP5 and the experiment design. Bull Am Meteorol Soc 93:485-498

van der Linden P, Mitchell JFB (eds) (2009) ENSEMBLES: climate change and its impacts: summary of research and results from the ENSEMBLES project. Met Office Hadley Centre, Exeter

Weitzman ML (2011) Fat-tailed uncertainty in the economics of catastrophic climate change. Rev Environ Econ Policy 5:275-292

Wilby RL, Dessai S (2010) Robust adaptation to climate change. Weather 65:180-185

Zhou Q, Mikkelsen PS, Halsnæs K, Arnbjerg-Nielsen K (2012) Framework for economic pluvial flood risk assessment considering climate change effects and adaptation benefits. J Hydrol (Amst) 414-415:539-549

\section{APPENDIX}

Table A1. Assumptions for flood damage cost calculations using the damage curve (DC) approach

\begin{tabular}{|c|c|c|c|c|c|c|c|c|}
\hline \multirow{2}{*}{$\frac{\text { Unit costs }}{\text { Buildings }}$} & \multicolumn{7}{|c|}{-Surface water depth } & \multirow[t]{2}{*}{ Unit } \\
\hline & $10 \mathrm{~cm}$ & $20 \mathrm{~cm}$ & $30 \mathrm{~cm}$ & $40 \mathrm{~cm}$ & $50 \mathrm{~cm}$ & $60 \mathrm{~cm}$ & $70 \mathrm{~cm}$ & \\
\hline Service and industry & 69418 & 138835 & 208253 & 277670 & 347088 & 416506 & 485923 & EUR/building \\
\hline Multistorage residential & 45561 & 91122 & 136684 & 182245 & 227806 & 273367 & 318928 & EUR/building \\
\hline Houses & 16667 & 33333 & 50000 & 66667 & 83333 & 100000 & 116667 & EUR/building \\
\hline Leisure house & 833 & 1667 & 2500 & 3333 & 4167 & 5000 & 5833 & EUR/building \\
\hline & $2.5 \mathrm{~cm}$ & $5 \mathrm{~cm}$ & $10 \mathrm{~cm}$ & $15 \mathrm{~cm}$ & $20 \mathrm{~cm}$ & $30 \mathrm{~cm}$ & $50 \mathrm{~cm}$ & \\
\hline Basements & 9 & 18 & 35 & 53 & 70 & 106 & 176 & $\mathrm{EUR} / \mathrm{m}^{2}$ \\
\hline & $2.5 \mathrm{~cm}$ & $5 \mathrm{~cm}$ & $10 \mathrm{~cm}$ & $15 \mathrm{~cm}$ & $20 \mathrm{~cm}$ & $30 \mathrm{~cm}$ & $50 \mathrm{~cm}$ & \\
\hline Roads & 9 & 18 & 35 & 53 & 70 & 106 & 176 & $\mathrm{EUR} / \mathrm{m}^{2}$ \\
\hline Railways & 44 & 88 & 176 & 264 & 352 & 528 & 881 & $\mathrm{EUR} / \mathrm{m}^{2}$ \\
\hline & $0.15 \mathrm{~cm}$ & $0.3 \mathrm{~cm}$ & $1 \mathrm{~cm}$ & $5 \mathrm{~cm}$ & $10 \mathrm{~cm}$ & $20 \mathrm{~cm}$ & $50 \mathrm{~cm}$ & \\
\hline Health & 11 & 22 & 72 & 361 & 722 & 1444 & 3610 & EUR/person \\
\hline & $10 \mathrm{~cm}$ & $20 \mathrm{~cm}$ & $30 \mathrm{~cm}$ & $40 \mathrm{~cm}$ & $50 \mathrm{~cm}$ & $60 \mathrm{~cm}$ & $70 \mathrm{~cm}$ & \\
\hline Waterbodies flooded in the city & 16667 & 33333 & 50000 & 66667 & 83333 & 100000 & 116667 & EUR/waterbody \\
\hline Irreplaceable assets & $10 \mathrm{~cm}$ & $20 \mathrm{~cm}$ & $30 \mathrm{~cm}$ & $40 \mathrm{~cm}$ & $50 \mathrm{~cm}$ & $60 \mathrm{~cm}$ & $70 \mathrm{~cm}$ & \\
\hline Ancient monuments & 33333 & 66667 & 100000 & 133333 & 166667 & 200000 & 233333 & EUR/building \\
\hline Churches & 333333 & 666667 & 1000000 & 1333333 & 1666667 & 2000000 & 2333333 & EUR/building \\
\hline Conservation worthy buildings & 33333 & 66667 & 100000 & 133333 & 166667 & 200000 & 233333 & EUR/building \\
\hline Clergy buildings middle age & 33333 & 66667 & 100000 & 133333 & 166667 & 200000 & 233333 & EUR/building \\
\hline Statues and sculptures & 33333 & 66667 & 100000 & 133333 & 166667 & 200000 & 233333 & EUR/building \\
\hline Museums & 333333 & 666667 & 1000000 & 1333333 & 1666667 & 2000000 & 2333333 & EUR/building \\
\hline
\end{tabular}


Table A2. Assumptions for flood damage cost calculations using the event-driven (ED) approach

\begin{tabular}{|c|c|c|c|c|c|c|c|}
\hline \multirow[t]{2}{*}{ Unit costs } & \multirow{2}{*}{$\begin{array}{l}\text { Water depth } \\
\text { threshold }(\mathrm{cm})\end{array}$} & \multicolumn{5}{|c|}{ Maximum event intensity $\left(\mathrm{mm} \mathrm{h}^{-1}\right)$} & \multirow[t]{2}{*}{ Unit } \\
\hline & & 20 & 25 & 30 & 35 & 40 & \\
\hline \multicolumn{8}{|l|}{ Buildings } \\
\hline Service and industry & 20 & 87972 & 182821 & 277670 & 372520 & 467369 & EUR/building \\
\hline Multi-storage residential & 20 & 45689 & 113967 & 182245 & 250523 & 318801 & EUR/building \\
\hline Houses & 20 & 43718 & 55192 & 66667 & 78141 & 89616 & EUR/building \\
\hline Leisure house & 20 & 1315 & 2324 & 3333 & 4342 & 5352 & EUR/building \\
\hline Basements & 5 & 33 & 47 & 67 & 87 & 100 & $\mathrm{EUR} / \mathrm{m}^{2}$ \\
\hline Roads & 5 & 167 & 233 & 333 & 433 & 500 & $\mathrm{EUR} / \mathrm{m}^{2}$ \\
\hline Railways & 5 & 33 & 47 & 67 & 87 & 100 & $\mathrm{EUR} / \mathrm{m}^{2}$ \\
\hline Health & 0.3 & 446 & 624 & 892 & 1159 & 1337 & EUR/person \\
\hline Waterbodies flooded in the city & 20 & 33333 & 46667 & 66667 & 86667 & 100000 & EUR/waterbody \\
\hline \multicolumn{8}{|l|}{ Irreplaceable assets } \\
\hline Ancient monuments & 20 & 66667 & 93333 & 133333 & 173333 & 200000 & EUR/building \\
\hline Churches & 20 & 666667 & 933333 & 1333333 & 1733333 & 2000000 & EUR/building \\
\hline Conservation worthy buildings & 20 & 66667 & 93333 & 133333 & 173333 & 200000 & EUR/building \\
\hline Clergy buildings middle age & 20 & 66667 & 93333 & 133333 & 173333 & 200000 & EUR/building \\
\hline Statues and sculptures & 20 & 66667 & 93333 & 133333 & 173333 & 200000 & EUR/building \\
\hline Museums & 20 & 666667 & 933333 & 1333333 & 1733333 & 2000000 & EUR/building \\
\hline
\end{tabular}

